\title{
Sphingosine-1-phosphate activates chemokine-promoted myeloma cell adhesion and migration involving a4 $\beta 1$ integrin function
}

\begin{tabular}{|c|c|}
\hline Journal: & Journal of Pathology \\
\hline Manuscript ID: & 12-126.R1 \\
\hline Wiley - Manuscript type: & Original Research Article \\
\hline Date Submitted by the Author: & $\mathrm{n} / \mathrm{a}$ \\
\hline Complete List of Authors: & $\begin{array}{l}\text { TEIXIDO, JOAQUIN; Centro de Investigaciones Biologicas, Immunology } \\
\text { Garcia-Bernal, David; Centro de Investigaciones Biológicas, Cellular and } \\
\text { Molecular Medicine Program } \\
\text { Redondo-Muñoz, Javier; Centro de Investigaciones Biológicas, Cellular and } \\
\text { Molecular Medicine Program } \\
\text { Dios-Esponera, Ana; Centro de Investigaciones Biológicas, Cellular and } \\
\text { Molecular Medicine Program } \\
\text { Chévre, Raphael; Centro Nacional de Investigaciones Cardiovasculares, } \\
\text { Atherothrombosis and Cardiovascular Imaging } \\
\text { Bailón, Elvira; Centro de Investigaciones Biológicas, Cellular and Molecular } \\
\text { Medicine Program } \\
\text { Garayoa, Mercedes; Centro de Investigación del Cáncer, Instituto de } \\
\text { Biología Molecular y Celular del Cáncer, Department of Hematology } \\
\text { Arellano-Sanchez, Nohemí; Centro de Investigaciones Biológicas, Cellular } \\
\text { and Molecular Medicine Program } \\
\text { C. Gutierrez, Norma; Hospital Universitario de Salamanca, Department of } \\
\text { Hematology } \\
\text { Hidalgo, Andres; Centro Nacional de Investigaciones Cardiovasculares, } \\
\text { Atherothrombosis and Cardiovascular Imaging } \\
\text { Garcia-Pardo, Angeles; Centro de Investigaciones Biológicas, Cellular and } \\
\text { Molecular Medicine Program }\end{array}$ \\
\hline Key Words : & $\begin{array}{l}\text { Multiple myeloma, Chemokines, Cell adhesion and migration, Integrins, } \\
\text { Bone marrow, Signalling }\end{array}$ \\
\hline \multicolumn{2}{|l|}{ File Designations: } \\
\hline \multicolumn{2}{|l|}{ Tissue: } \\
\hline \multicolumn{2}{|l|}{ Pathology: } \\
\hline Technique: & \\
\hline
\end{tabular}




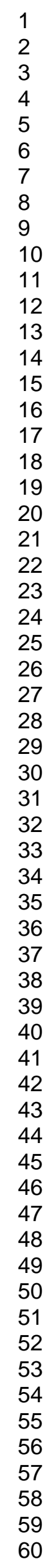

SCHOLARONE"

Manuscripts

7

25

26

27

29

30

32

33

34

36

37

39

40

41

42

44

45

46

47

48

50

51

52

53

54

56

57

58

60

http://mc.manuscriptcentral.com/jpath 


\section{Sphingosine-1-phosphate activates chemokine-promoted myeloma cell adhesion and migration involving $\alpha 4 \beta 1$ integrin function}

Running title: S1P regulates myeloma cell adhesion and migration

David García-Bernal ${ }^{1 *}$, Javier Redondo-Muñoz ${ }^{1 *}$, Ana Dios-Esponera ${ }^{1}$, Raphaël Chèvre $^{2}$, Elvira Bailón ${ }^{1}$, Mercedes Garayoa ${ }^{3}$, Nohemí Arellano-Sánchez ${ }^{1}$, Norma C. Gutierrez $^{4}$, Andrés Hidalgo ${ }^{2}$, Angeles García-Pardo ${ }^{1}$ and Joaquin Teixidó ${ }^{1}$

From: ${ }^{1}$ Cellular and Molecular Medicine Program, Centro de Investigaciones Biológicas (CSIC), 28040 Madrid, Spain

${ }^{2}$ Department of Epidemiology, Atherothrombosis and Cardiovascular Imaging, Centro Nacional de Investigaciones Cardiovasculares (CNIC), 28029 Madrid, Spain

${ }^{3}$ Department of Hematology, Centro de Investigación del Cáncer, Instituto de Biología Molecular y Celular del Cáncer (CSIC), 37007 Salamanca, Spain

${ }^{4}$ Department of Hematology, Hospital Universitario de Salamanca, 37007 Salamanca, Spain.

*These authors contributed equally to this work.

Corresponding author: Joaquin Teixidó. Centro de Investigaciones Biológicas, Cellular and Molecular Medicine Program. Ramiro de Maeztu 9, 28040 Madrid, Spain.

Phone 34-91-8373112; Fax 34-91-5360432; e-mail: joaquint@cib.csic.es

Conflict of interest: The authors declare no competing financial interests in relation to the work described. 
Myeloma cell adhesion dependent on $\alpha 4 \beta 1$ integrin is crucial for progression of multiple myeloma (MM). The $\alpha 4 \beta 1$-dependent myeloma cell adhesion is upregulated by the chemokine CXCL12, and pharmacological blockade of the CXCL12 receptor CXCR4 leads to defective myeloma cell homing to bone marrow (BM). Sphingosine-1phosphate (S1P) regulates immune cell trafficking upon binding to G-protein-coupled receptors. Here we show that myeloma cells express $\mathrm{S} 1 \mathrm{P} 1$, a receptor for S1P. We found that S1P upregulated the $\alpha 4 \beta 1$-mediated myeloma cell adhesion and transendothelial migration stimulated by CXCL12. S1P promoted generation of highaffinity $\alpha 4 \beta 1$ that efficiently bound the $\alpha 4 \beta 1$ ligand VCAM-1, a finding that was associated with S1P-triggered increase in talin- $\beta 1$ integrin association. Furthermore, S1P cooperated with CXCL12 for enhancement of $\alpha 4 \beta 1$-dependent adhesion strengthening and spreading. CXCL12 and S1P activated the DOCK2-Rac1 pathway, which was required for stimulation of myeloma cell adhesion involving $\alpha 4 \beta 1$. Moreover, in vivo analyses indicated that S1P contributes to optimize the interactions of MM cells with the BM microvasculture and for their lodging inside the bone marrow.

The regulation of $\alpha 4 \beta 1$-dependent adhesion and migration of myeloma cells by CXCL12-S1P combined activities might have important consequences for myeloma disease progression.

Keywords: Multiple myeloma, Chemokines, Cell adhesion and migration, Integrins, Bone marrow, Signalling 


\section{INTRODUCTION}

In multiple myeloma (MM) malignant plasma cells home to and accumulate in different niches within the bone marrow (BM) microenvironment [1-3]. The chemokine-receptor axis CXCL12-CXCR4 and the integrins $\alpha 4 \beta 1$ and $\alpha 5 \beta 1$ have been proposed to mediate myeloma cell trafficking to the BM [4,5]. The in vivo relevance of CXCL12-CXCR4 in MM is highlighted by the fact that the CXCR4 inhibitor AMD3100 impairs homing of myeloma cells by disrupting their interaction with the BM microenvironment [6,7]. CXCL12 binding to CXCR4 triggers inside-out signalling leading to $\alpha 4 \beta 1$ - and $\alpha 5 \beta 1$-dependent stimulation of myeloma cell adhesion [4]. $\alpha 4 \beta 1$ mediated myeloma cell adhesion is crucial for $\mathrm{MM}$ progression in vivo, as anti- $\alpha 4$ antibodies inhibit this adhesion and the development of MM and associated osteolysis [8,9]. Moreover, cell adhesion-mediated drug resistance in MM involves $\alpha 4 \beta 1$ activity $[10,11]$

Sphingosine-1-phosphate (S1P) is a lipid produced during sphingolipid turnover, that is generated by sphingosine kinase-catalysed phosphorylation of sphingosine [1214], and dephosphorylated by S1P phosphatases or degraded by S1P lyases [14]. S1P is found in plasma and lymph, mainly produced by red blood cells and by the lymphatic endothelium $[15,16][17]$. The five S1P receptors (S1P1 through S1P5) belong to the $\mathrm{G}$ protein-coupled receptor family, and among them, S1P1 controls lymphocyte egress from thymus, spleen and lymph nodes (LN) [16,18-24], as well as plasma cell egress from LNs [25]. The first clues for S1P involvement in lymphocyte egress came from studies with the S1P analogue FTY720 phosphate, which binds to four out of the five S1P receptors, including S1P1 [19,26]. Similarly to S1P1 deficiency, FTY720 promotes lymphopenia due to T cell sequestration in LNs $[19,20]$. 
Besides controlling egress from secondary lymphoid organs (SLO), S1P1 regulates immature $\mathrm{B}$ cell and hematopoietic progenitor cell egress from BM [27-29]. Importantly, S1P1 also facilitates integrin activation during $\mathrm{T}$ cell homing to SLO $[23,30]$, and supports CXCR4-dependent migration and BM homing of human CD34 ${ }^{+}$ progenitor cells [31]. Finally, recent data showed that S1P stimulates $\alpha 4 \beta 1$-dependent CFU-GM adhesion to BM stroma [32].

There is increasing evidence for S1P involvement in cancer progression. Thus, $\mathrm{S} 1 \mathrm{P}$ regulates tumor cell growth and survival, as well as tumor cell invasion and metastasis $[33,34]$. Sphingosine kinase 1 expression is augmented in non-Hodgkin's lymphoma [35], and a significant cohort of leukaemia samples displayed S1P1 and S1P5 overexpression [36]. Interestingly, high levels of S1P1 on T-lymphoblastic lymphoma cells led to changes in cell adhesion [37]. A potential role for S1P on myeloma cell trafficking has not yet been studied. In the present study we have investigated whether S1P can influence CXCL12-promoted myeloma cell migration and adhesion involving $\alpha 4 \beta 1$ and $\alpha 5 \beta 1$. Our results indicate that S1P activates these integrins and cooperate with CXCL12 to increase myeloma cell adhesion strengthening and spreading, suggesting that the combined actions of these stimuli might control myeloma cell trafficking and therefore influence MM progression. 


\section{MATERIALS AND METHODS}

Cells, transfections and RT-PCR. CD $138^{+}$primary myeloma cells were purified (88$95 \%$ purification) from the mononuclear fractions of BM samples from patients with active MM using CD138 microbeads (Miltenyi Biotec, Bergisch Gladbach, Germany). MM-BM stroma cultures were generated as described [38], and used at passage 3. This study was approved by the Institutional Review Board of the University Hospital of Salamanca, and by the Scientific and Ethics Committee of the Spanish Program for the Study and Treatment of Malignant Hemopathies. siRNA were nucleofected using solution V and programs T-01 and O-23 (Amaxa, Cologne, Germany) for NCI-H929 and MM1.S, respectively, and transfectants assayed $22 \mathrm{~h}$ post-transfectiond [39]. For RT-PCR, cells were lysed, RNA extracted and reverse transcribed as documented [39]. Oligonucleotide sequences are provided in the Supporting Information. The PCR profiles consisted of 35 cycles of 1 -min melting at $94^{\circ} \mathrm{C}$ for $1 \mathrm{~min}$, followed by annealing at $60^{\circ} \mathrm{C}$ for $45 \mathrm{sec}$ for $\mathrm{S} 1 \mathrm{P} 1$ or $64^{\circ} \mathrm{C}$ for 1 min for $\mathrm{S} 1 \mathrm{P} 4$, and elongation at $72^{\circ} \mathrm{C}$ during $30 \mathrm{sec}$ for $\mathrm{S} 1 \mathrm{P} 1$ or $1 \mathrm{~min}$ for $\mathrm{S} 1 \mathrm{P} 4$. Aliquots of each sample were amplified using the same conditions with human GAPDH primers.

Detection of S1P activity in MM-BM samples and myeloma cells. K562 cells transfected with the S1P1-HA vector were used as sensors for S1P presence in the different samples. Transfectants were incubated for $16 \mathrm{~h}$ with whole MM-BM aspirates (0.5 ml), MM-BM plasma (obtained after ficoll-paque gradient; $0.5 \mathrm{ml}$ ), or serum-free supernatants from purified $\mathrm{CD} 138^{+}$or NCI-H929 cells. The MM-BM stroma or cocultures of MM-BM stroma/NCI-H929 cells were incubated in serum-free medium for $24 \mathrm{~h}$ before collecting the supernatants for subsequent incubation with S1P1-HA transfectants. Finally, transfectants were subjected to flow cytometry with anti-S1P1 antibodies (see supporting information). 
Cell adhesion, migration and soluble binding assays. For static adhesions, cells were placed on wells coated with CXCL12 together with either plasma fibronectin (Roche Diagnostics, Penzberg, Germany), fibronectin fragments FN-80 (contains the RGD sequence), or FN-H89 (contains the CS-1 domain) [39,40], or with VCAM-1, and plates incubated for $2 \mathrm{~min}$ at $37^{\circ} \mathrm{C}$ in the absence or presence of soluble $\mathrm{S} 1 \mathrm{P}$, as described [39]. Attachment to MM-BM stroma was also for 2 min at $37^{\circ} \mathrm{C}$, but adding soluble stimuli. Adhesions were quantified with a fluorescence analyzer. Flow chamber adhesion assays were performed as reported [41]. Briefly, myeloma cells with or without S1P were infused into flow chambers containing co-immobilized VCAM-1 and CXCL12. Rolling cells firmly attaching for at least $20 \mathrm{sec}$ were expressed as stable arrest, whereas tethering cells that did not arrest at any moment were expressed as rolling cells. To evaluate shear resistance, cells were allowed to attach, and then were subjected to sequential flow rate increases. Myeloma cell migration across TNF- $\alpha$ treated human umbilical vein endothelial cells (HUVEC) and chemotaxis assays were done as described [42], and migrated cells counted by flow cytometry. For soluble binding, transfectants were stimulated for $20 \mathrm{sec}$ with CXCL12 and/or S1P before adding VCAM-1-Fc, which was detected by flow cytometry [39]. In binding experiments using the $15 / 7 \mathrm{mAb}$, cells were exposed for $30 \mathrm{sec}$ to the different stimuli before addition of the antibody.

Cellular spreading, GTPase and actin polymerization assays. Cell spreading on FNH89 was analyzed by Nomarski and by interference reflexion microscopy (IRM), and percentage of cell spreading was determined from a significant number of cells from different fields of view ( $\mathrm{n}=2500-3000)$ [43]. GTPase assays were performed as reported [39]. Briefly, cells exposed to CXCL12 were lysed, and aliquots separated for total lysate controls and for incubation with GST-PAK-CD (for active Rac1) or GST-Ral-GDS (for 
active Rap1) fusion proteins and glutathione-agarose beads. Bound proteins were eluted and subjected to immunoblotting using anti-Rac1 or anti-Rap1 antibodies. Cellular Factin content was measured by flow cytometry following a single permeabilization, fixation and staining step [4].

Intravital microscopy and in vivo myeloma cell lodging in the bone marrow. MM1.S cells were incubated for $12 \mathrm{~h}$ with S1P $(250 \mathrm{nM})$ or medium alone, and receptor internalization was confirmed by flow cytometry. Cells were then washed and labelled with DiD Vybrant cell labeling Kit (Molecular Probes, Eugene, OR, USA), and $5 \times 10^{6}$ labelled cells injected intravenously into NOD/SCID mice in each group. 30 min after injection, mice were sacrificed and the total number of MM1.S cells migrating to the $\mathrm{BM}$ of the two femurs was determined by flow cytometry. For intravital microscopy analyses, 5x10 $0^{6}$ CFSE-labelled NCI-H929 cells transfected with control or S1P1 siRNA were injected intravenously at the time of imaging through a catheter placed in the left carotid artery. Five week-old NOD/SCID mice were prepared for intravital imaging of the calvarial bone as indicated previously [44], and images acquired using a Leika DM6000 epifluorescence microscope. Collecting venules (Cv) and sinusoid (S) have been anatomically defined before, and are functionally associated with early engraftment in mouse models $[44,45]$. The number of rolling and adherent cells (arrested $>3 \mathrm{~s}$ ), as well as hemodynamic parameters were analyzed by blind off-line video analysis. For each vessel we measured the maximum blood velocity (Vmax) from the fastest free-flowing cells, as well as vessel diameter (Dv), mean velocity (Vmean) and wall shear rate (WSR) by applying the following formulas: $\mathrm{Vmean}=\mathrm{Vmax} /\left(2-\varepsilon^{2}\right)$, where $\varepsilon=\mathrm{Dc} / \mathrm{Dv}$, and the cell diameter (Dc) for NCI-H929 cells is $8 \mu \mathrm{m}$. WSR $=$ $8(\mathrm{Vmean} / \mathrm{Dv})$, and Vcrit $=$ Vmean $\times \varepsilon(2-\varepsilon)$. Any cell traveling below Vcrit was considered to be rolling on the vessel wall. Cells that remained stationary for 3 seconds 
or more were considered arrested. The fraction of cells that rolled or arrested according to these criteria were scored from the movies. Animal procedures were performed in accordance with guidelines of the Ethical Committee at CNIC.

Statistical analyses. Data were analyzed by one-way analysis of variance (ANOVA), followed by Tukey-Kramer multiple comparisons. In both analyses, the minimum acceptable level of significance was $\mathrm{p}<0.05$. 


\section{RESULTS}

Expression of S1P receptors on myeloma cells. The myeloma cell lines NCI-H929, MM1.S, U266 and RPMI 8226 expressed S1P1, as well as traces of S1P4, as detected by RT-PCR (Figure 1A). Expression of S1P1 and S1P4 was nearly undetectable in OPM-2 myeloma cells. Moreover, CD138 ${ }^{+}$myeloma cells purified from 6 different BM aspirates from MM patients (MM-BM) expressed S1P1 and low amounts of S1P4 (Figure 1B, left). Flow cytometry analyses revealed surface expression of S1P1 in all MM-BM CD $138^{+}$myeloma cell samples, which was consistently slightly lower than CXCR4 surface expression (Figure 1B, right). Molt-4 T cells were used as positive controls for detection of S1P receptors.

Recent data showed that $\mathrm{S} 1 \mathrm{P}$ is present in the $\mathrm{BM}$ microenvironment [32]. As S1P binding to S1P1 leads to receptor internalization [18], we employed a $\mathrm{S}_{\mathrm{P}} 1^{+}$cell line in a flow cytometry bioassay to determine if S1P activity could be found in MMBM samples. We chose K562 cells transfected with S1P1-HA (K562/S1P1-HA) (Supporting information, Figure 1A), as they responded to low S1P concentrations in the bioassay (Supporting information, Figure 1B). Exposure of K562/S1P1-HA transfectants to different unprocessed MM-BM samples or to their corresponding plasma resulted in $45-75 \%$ reduction of surface S1P1-HA expression (Figure 1C, left). Likewise, supernatants from MM-BM stroma or from NCI-H929/MM-BM stroma cocultures also reduced S1P1-HA expression by 50-60\% (Figure 1C, right). In contrast, supernatants from purified CD138 ${ }^{+}$or NCI-H929 myeloma cells did not alter S1P1-HA membrane expression (Figure 1C). These results reveal the presence of S1P in the MMBM microenvironment, and indicate that stromal cells represent a source for S1P.

S1P upregulates CXCL12-stimulated myeloma cell migration. Neither NCI-H929, MM1.S or CD138 $8^{+}$MM-BM cells migrated towards S1P in chemotaxis chamber assays 
(Figure 2A). Instead, they migrated to CXCL12, as previously reported [4]. Interestingly, S1P significantly stimulated CXCL12-triggered myeloma cell chemotaxis in $30 \mathrm{~min}$ assays (Figure 2A), although this effect was lost after longer incubations (see Supporting information, Figure 1C), indicating that S1P effect was transient. S1P did not alter CXCR4 or $\beta 1$ integrin expression (Supporting information, Figure 1D), and CXCL12 did not affect S1P1 expression (not shown).

To investigate potential cross-talks between CXCR4 and S1P1, we performed chemotaxis assays using NCI-H929 cells transfected with CXCR4 or S1P1 siRNA, which reduced CXCR4 or S1P1 surface expression by 60 and $70 \%$, respectively (Figure 2B). Chemotaxis to CXCL12 was abolished in CXCR4-silenced transfectants, but was fully retained in S1P1 siRNA transfectants (Figure 2C). Furthermore, upregulated of chemotaxis by combination of CXCL12 and S1P was reversed in S1P1-depleted transfectants to levels similar to control counterparts migrating to CXCL12 alone, while CXCR4 silencing blocked transfectant chemotaxis to the combined stimuli. These results indicate that S1P requires CXCR4-dependent signalling to upregulate CXCL12triggered myeloma cell migration.

To functionally assess CXCL12 and S1P activities in MM-BM stroma supernatants, we used these supernatants as stimuli in chemotaxis assays using CXCR4or S1P1-silenced myeloma cells. Migration of CXCR4 and S1P1 siRNA transfectants to the stroma supernatants was inhibited by $75 \%$ and $50 \%$, respectively, compared to control siRNA transfectants (Figure 2D), indicating that MM-BM stroma supernatants contain functional CXCL12 and S1P activities.

\section{S1P stimulates CXCL12-promoted myeloma cell adhesion involving integrins $\alpha 4 \beta 1$}

and $\boldsymbol{\alpha} \mathbf{5} \boldsymbol{\beta} \mathbf{1}$. Next, we exposed myeloma cells to S1P in integrin-dependent static adhesion assays. The $\alpha 4 \beta 1$ ligands FN-H89 and VCAM-1, the $\alpha 5 \beta 1$ ligand FN-80, as 
well as total fibronectin were immobilized with or without CXCL12, and adhesion assays performed for 2-min periods, as chemokine-activated cell adhesion is best detected using short times. S1P alone did not induce myeloma cell attachment to any of these ligands, but it significantly upregulated CXCL12-promoted adhesion (Figure 3A, B). This was independent of the potential presence of fatty acids in the BSA included in the adhesion medium (Supporting information, Figure 2A). Combination of CXCL12 and S1P increased OPM-2 cell adhesion to FN-H89, but enhancement was nonsignificant ( $>0.05$; not shown). Increase in myeloma cell adhesion to VCAM-1 was already detected at 50-100 nM S1P concentrations (Supporting information, Figure 2B). The S1P analogue FTY720 [14] had by itself no effect on myeloma cell adhesion, but it increased CXCL12-stimulated attachment, albeit with lower potency than S1P (Supporting information, Figure 2C). As NCI-H929 and MM1.S cells generally gave the best responses to CXCL12/S1P in chemotaxis and adhesion assays, we used these cells in the foregoing experiments.

Similarly to cell migration, stimulation of $\alpha 4 \beta 1$-mediated cell adhesion by CXCL12 was fully preserved in S1P1-silenced transfectants, whereas it was blocked in CXCR4-knockdown cells (Figure 3C). Further upregulation of adhesion by CXCL12/ S1P was reduced in S1P1-depleted cells to levels similar to control siRNA transfectants stimulated with CXCL12 alone.

CXCL12 or S1P promoted myeloma cell binding of 15/7, a mAb that recognizes a $\beta 1$ integrin activation epitope on $\alpha 4 \beta 1$ [46], as well as the binding of VCAM-1-Fc (Figure 4A). In addition, combining both stimuli further increased the binding, revealing the acquisition of high-affinity $\alpha 4 \beta 1$ conformations. Control experiments indicated that anti- $\alpha 4$ antibodies blocked VCAM-1-Fc binding to stimulated cells (not shown). 
Talin interaction with integrin $\beta$ subunits is associated with integrin activation [47]. Co-immunoprecipitation assays revealed that talin- $\beta 1$ association was enhanced by CXCL12 or S1P in myeloma cells, and further augmented upon exposure to both chemoattractants (Figure 4B, left). Increased talin- $\beta 1$ association was inhibited in S1P1depleted transfectants (Figure 4B, right), stressing S1P involvement in promoting integrin activation. As chemokines trigger the association between their receptors and G $\alpha$ subunits of heterotrimeric proteins, we analyzed CXCR4-G $\alpha_{i}$ association in cells incubated with S1P. Interestingly, CXCR4-G $\alpha_{\mathrm{i}}$ association triggered by CXCL12 was stronger by combined CXCL12 and S1P (Figure 4C), suggesting that S1P may potentiate CXCL12-dependent signalling, which could represent a mechanism accounting for upregulation of $\alpha 4 \beta 1$-dependent adhesion.

Adhesion assays under shear stress revealed that S1P alone was unable to promote NCI-H929 and MM1.S firm arrest on VCAM-1, and thus most cells mainly rolled (Figure 5A). Instead, CXCL12 immobilized with VCAM-1 induced strong cell arrest. We could not detect further increases of cell arrest by S1P over that promoted by CXCL12, which might reflect the already high adhesion level triggered by CXCL12. Control experiments showed adhesion blockade by cell pre-treatment with pertussis toxin or anti- $\alpha 4 \mathrm{mAb}$ (not shown). Notably, when flow was stopped and cells allowed to settle, myeloma cells that attached to VCAM-1 after exposure to CXCL12/S1P developed higher resistance to detachment at increased shear stress than those incubated with CXCL12 alone (Figure 5B).

Interestingly, S1P could not trigger cell spreading, whereas CXCL12 promoted robust spreading that was stronger with the combined stimuli (Figure 5C). In addition, the extent of polymerized actin, a process required for cell spreading and migration, was also higher in cells incubated with both stimuli (Figure 5D). Together, these data 
indicate that S1P promotes high-affinity $\alpha 4 \beta 1$ conformations in myeloma cells, but needs CXCL12 to stimulate adhesion strengthening and spreading leading to adhesion stabilization.

DOCK2-Rac1 signalling is required for CXCL12- and CXCL12/S1P-stimulated myeloma cell adhesion. CXCL12 activates the GTPase Rac1 in myeloma cells $[42,48]$. DOCK2 is a scaffolding protein that regulates actin dynamics by promoting Rac activation [49]. DOCK2 silencing in NCI-H929 cells led to defective Rac1 activation in response to S1P, CXCL12 or both, and to a blockade of stimulation of cell adhesion to VCAM-1 (Figure 6A, B). Furthermore, CXCL12- or CXCL12/S1P-stimulated cell attachment to VCAM-1 was abrogated in Rac1-depleted cells (Figure 6C), together indicating that activation of $\alpha 4 \beta 1$-dependent myeloma cell adhesion requires DOCK2Rac1 signalling.

Activation of the GTPase Rap1 by chemokines has been linked to lymphocyte integrin activation [50]. NCI-H929 cells displayed rapid Rap1 activation in response to CXCL12, S1P or both (Figure 6D). Contrary to DOCK2 or Rac1, Rap1 silencing did not affect stimulation of myeloma cell attachment to VCAM-1 when exposed to CXCL12 or CXCL12/S1P (Figure 6E), indicating that upregulated adhesion does not require Rap1 activation.

S1P upregulates CXCL12-stimulated myeloma cell adhesion to MM stroma and transendothelial migration involving $\alpha 4 \beta 1$ and $\alpha 5 \beta 1$. CXCL12-promoted adhesion of NCI-H929 and CD138 ${ }^{+}$MM-BM cells to MM-BM stroma was enhanced by S1P and it was dependent on both $\alpha 4 \beta 1$ and $\alpha 5 \beta 1$, whereas S1P alone did not trigger adhesion (Figure 7A). CXCR4 silencing blocked CXCL12- or CXCL12/S1P-induced cell attachment to BM stroma, while S1P1 depletion reduced the adhesion promoted by both stimuli to the levels of control siRNA transfectants stimulated by CXCL12 (Figure 7B). 
Moreover, S1P further increased $\alpha 4 \beta 1$-mediated myeloma cell transendothelial migration to CXCL12, whereas no migration was detected with S1P alone (Figure 7C). Role of S1P during myeloma cell trafficking to BM. The CXCL12-CXCR4 axis mediates in vivo myeloma cell homing to $\mathrm{BM}[6,7]$. To investigate $\mathrm{S} 1 \mathrm{P} 1$ contribution to in vivo MM cell migration, we measured the lodging in the BM of NOD-SCID mice of labelled MM1.S cells whose S1P1 surface expression had been down-regulated by preincubation with S1P (Figure 7D, top). S1P treatment led to a modest, but statistically significant reduction in MM1.S cell lodging (mean 22\% inhibition, $p<0.05$ ) (Figure 7D, bottom). A slight increase (20\%) in S1P-treated cells in blood was detected compared to control ones, but differences were not statistically significant ( $p>0.05$, not shown). To identify mechanisms by which S1P1 contributes to MM cell lodging, we performed intravital imaging of NOD/SCID BM microcirculation at the time of injection of fluorescently-labelled myeloma cells. Both the capacity to roll and firmly arrest on the BM microvasculature were reduced in S1P1-silenced cells relative to control transfectants (Figure 7E; table 1; supporting information Figure 3, and videos 1-3). Collectively, these results indicate that S1P1-derived signals are important for optimal MM cell interaction with the BM microvasculature under physiological flow conditions, and for their efficient migration inside the BM. 


\section{DISCUSSION}

Adhesion of myeloma cells involving $\alpha 4 \beta 1$ is crucial for MM progression [8,9], and mediates cell adhesion-dependent drug resistance $[10,11]$. CXCL12 activates $\alpha 4 \beta 1$ in myeloma cells through inside-out signalling [4], which is likely the target of AMD3100, a CXCR4 inhibitor that impairs myeloma cell homing to BM [6].

$\mathrm{S} 1 \mathrm{P}$ regulates hematopoietic progenitor and plasma cell localization in the $\mathrm{BM}$ $[25,29]$. Here we show that CD138 $8^{+}$MM-BM cells express S1P1, in agreement with previous results [51] and with MM cell transcriptome profiles from the Oncomine database. Furthermore, we found that MM-BM stromal cells secrete S1P. Notably, S1P enhanced myeloma cell chemotaxis promoted by CXCL12, as well as chemokinetriggered cell adhesion mediated by $\alpha 4 \beta 1$ and $\alpha 5 \beta 1$. In addition, CXCL12-activated myeloma cell transendothelial migration involving $\alpha 4 \beta 1$ function was also stimulated by S1P. Finally, we found that S1P1 is needed for optimal interaction of MM cells with the $\mathrm{BM}$ microvasculature in vivo, contributing to their lodgement inside the $\mathrm{BM}$

Experiments with S1P1- or CXCR4-silenced myeloma cells revealed that S1P requires CXCR4-dependent signalling to upregulate cell adhesion and migration triggered by CXCL12. Thus, following CXCR4 depletion, S1P was unable to induce CXCL12-stimulated cell adhesion or migration, whereas S1P1-silenced cells retained full CXCL12 responsiveness. Interestingly, S1P increased CXCR4-G $\alpha_{i}$ association triggered by CXCL12, suggesting that S1P acts by enhancing CXCL12-dependent signalling leading to upregulated myeloma cell adhesion and migration.

Although S1P by itself could not increase $\alpha 4 \beta 1$-dependent myeloma cell adhesion, it promoted $\alpha 4 \beta 1$ high-affinity conformations. Moreover, S1P alone or combined with CXCL12 stimulated talin- $\beta 1$ association, an additional indication of integrin activation [47]. Besides increasing $\alpha 4 \beta 1$ affinity, a requirement during the 
initial phases of adhesion, our cell detachment analyses in flow chambers revealed that the subsequent adhesion strengthening step involving increased avidity was also targetted by S1P, but only in combination with CXCL12. Furthermore, the later cell spreading phase in the adhesion cascade was also increased by S1P acting together with CXCL12. Therefore, our data indicate that S1P upregulates chemokine-activated myeloma cell adhesion by further stimulating or maintaining high-affinity $\alpha 4 \beta 1$ conformations at early cell attachment steps, and by working together with CXCL12 to increase adhesion strengthening and cell spreading. Our results are in line with previous data showing that combined chemokine receptor and S1P1 activation increases $\alpha 4 \beta 1$ and LFA-1-mediated T cell attachment to endothelium [52]. Similarly, FTY720 was found to support CXCR4-dependent migration and BM homing of progenitor cells involving $\alpha 4 \beta 1$ function [31], and S1P1 absence attenuated chemokine-promoted, integrin-mediated firm arrest on high endothelial venules, resulting in decreased cell homing to LNs [23].

Investigation of pathways required for stimulation of $\alpha 4 \beta 1$-mediated myeloma cell adhesion revealed that activation of DOCK2-Rac1 signalling is needed for CXCL12- and CXCL12/S1P-promoted cell attachment. We previously reported that CXCL12 activates Rac1 in myeloma cells [42], and we show here that Rac1 is also activated by S1P in these cells, consistent with earlier data on S1P-triggered Rac1 activation in vascular endothelium [53]. We demonstrate that DOCK2 is upstream of Rac1 activation in myeloma cells, and controls upregulated $\alpha 4 \beta 1$-dependent cell adhesion by CXCL12 and S1P. Earlier results revealed that DOCK2 $2^{-/-}$B cells in LNs are deficient in chemokine-promoted adhesion to VCAM-1 [54]. Interestingly, these cells displayed reduced motility inside the LN B cell follicle and defective F-actin polymerization due to S1P [55], again stressing the important role of DOCK2 in cell 
trafficking involving integrin function. Although we have not studied which adhesion steps require DOCK2-Rac1 activation in myeloma cells, based on our previous results with $\mathrm{T}$ cells silenced for both proteins $[39,41]$, it is likely that the adhesion strengthening and spreading are the steps mostly affected. Recent work also reported a Rac1 involvement in myeloma cell adhesion to fibronectin [48], although the experimental conditions were significantly different from ours $(2 \mathrm{~h}$ versus $2 \mathrm{~min}$ adhesions in our conditions). Together, our results indicate that activation of DOCK2dependent signalling leading to stimulation of $\alpha 4 \beta 1$ function could control the trafficking of myeloma cells and affect disease progression.

Both CXCL12 and S1P activated Rap1 in myeloma cells, yet Rap1 depletion did not affect the upregulated $\alpha 4 \beta 1$-dependent adhesion. Chemokine-activated $\mathrm{T}$ cell adhesion involving Rap1 is mostly associated with LFA-1-mediated attachment [50], whereas $\alpha 4 \beta 1$-dependent adhesion regulated by Rap1 was proposed [50], but also found not to be required [56]. In murine mature B cells, expression of RapGAPII impaired chemokine-triggered adhesion to VCAM-1 [57]. Conversely, our results indicate that Rap1 activation by chemokines in human myeloma cells is uncoupled to the stimulation of $\alpha 4 \beta 1$-mediated adhesion.

Our in vivo data indicate that S1P participates in MM cell lodging in the BM. S1P present in plasma might pre-activate $\alpha 4 \beta 1$ on circulating myeloma cells, but firm adherence on endothelium will still require CXCL12 actions. Therefore, cooperation between S1P and CXCL12 could be important for myeloma cell arrest on BM endothelium. Indeed, our results show that S1P1 contributes to optimal rolling and firm arrest of MM cells onto the BM microvasculature under conditions of physiological flow. In an in vivo context, $\alpha 4 \beta 1$ pre-activation by S1P might facilitate rolling on VCAM-1 or MadCAM-1 [58] present on the BM endothelium [59], while constitutive 
CXCL12 expression in the BM could complete firm arrest and extravasation in this tissue. Inside the $\mathrm{BM}$ microenvironment, S1P might contribute to myeloma cell localization by stimulating adhesion to fibronectin and to stromal VCAM-1 dependent on CXCL12. It is possible that high myeloma cell adhesion inside BM due to CXCL12S1P actions could increase cell survival, or it might also render these cells more resistant to drug-induced apoptosis [10]. S1P1 promotes B cell release from BM when CXCR4 signalling is weakened [28]. Therefore, S1P gradients from BM niches with low amounts of CXCL12 to high S1P levels in blood may constitute a mechanism facilitating myeloma cell egress from BM for further tissue colonization.

In conclusion, our results identify $\mathrm{S} 1 \mathrm{P}$ as a factor stimulating myeloma cell adhesion in combination with CXCL12, a finding that should shed more light on the trafficking of myeloma cells during MM progression. Interestingly, FTY720 induces apoptosis in MM cells [60], and thus it will be interesting to study potential connections between this observation and our results. 


\section{ACKNOWLEDGMENTS}

We thank the multiple myeloma patients who donated bone marrow samples for this research. Drs. Ana Arda Freire, Maria Iluminada Fernández López-Lucendo, Ignacio Casal and Jesús Jiménez Barbero are acknowledged for their experimental help at some parts of the work, and Dr. Jesús San Miguel for support and helpful discussions. This work was supported by the following grants from Ministerio de Ciencia e Innovación: SAF2011-24022 to J.T; SAF2009-07035 to A.G.P., SAF2009-11037 to A.H., RD06/0020/0011 to J.T. and A.G.P., RD06/0020/0006 to N.C.G and M.G., PI081825 to M.G. The work was also funded by grant P2010/BMD-2314 from the Comunidad de Madrid to A.G.P., J.T. and A.H., and by two grants from the Fundación de Investigación Médica Mutua Madrileña to A.G-P and M.G. A.H. is also funded by a FP7-People-2009-RG grant (\# 246655), a Ramón y Cajal Fellowship (RYC-200700697) and by the Pro-CNIC Foundation.

\section{STATEMENT OF AUTHOR CONTRIBUTIONS}

DG-B and JR-M carried out most experiments and analyzed data. AD-E, RC, EB and NA-S performed some of the experiments. MG prepared bone marrow stromal cultures. NG obtained bone marrow samples from multiple myeloma samples. JT, AG-P and AH conceived the experiments, analyzed data, wrote the paper and had final approval of the submitted version.

\section{LIST OF ONLINE SUPPORTING INFORMATION}

Figure S1. S1P1 internalization in K562 cells expressing transfected S1P1, and S1P role in myeloma cell migration.

Figure S2. Upregulation by S1P and FTY720 of CXCL12-promoted myeloma cell adhesion mediated by the integrin $\alpha 4 \beta 1$.

http://mc.manuscriptcentral.com/jpath 


\section{REFERENCES}

1. Bergsagel PL, Kuehl WM. Molecular pathogenesis and a consequent classification of multiple myeloma. J Clin Oncol 2005; 23: 6333-6338.

2. Hideshima $\mathrm{T}$, Mitsiades $\mathrm{C}$, Tonon $\mathrm{G}$, et al. Understanding multiple myeloma pathogenesis in the bone marrow to identify new therapeutic targets. Nat Rev Cancer 2007; 7: 585-598.

3. Kyle RA, Rajkumar SV. Multiple myeloma. Blood 2008; 111: 2962-2972.

4. Sanz-Rodriguez F, Hidalgo A, Teixido J. Chemokine stromal cell-derived factor-1alpha modulates VLA-4 integrin-mediated multiple myeloma cell adhesion to CS-1/fibronectin and VCAM-1. Blood 2001; 97: 346-351.

5. Parmo-Cabanas M, Molina-Ortiz I, Matias-Roman S, et al. Role of metalloproteinases MMP-9 and MT1-MMP in CXCL12-promoted myeloma cell invasion across basement membranes. J Pathol 2006; 208: 108-118.

6. Alsayed Y, Ngo H, Runnels J, et al. Mechanisms of regulation of CXCR4/SDF1 (CXCL12)-dependent migration and homing in multiple myeloma. Blood 2007; 109: 2708-2717.

7. Azab AK, Runnels JM, Pitsillides C, et al. CXCR4 inhibitor AMD3100 disrupts the interaction of multiple myeloma cells with the bone marrow microenvironment and enhances their sensitivity to therapy. Blood 2009; 113: 4341-4351.

8. Mori Y, Shimizu N, Dallas M, et al. Anti-alpha4 integrin antibody suppresses the development of multiple myeloma and associated osteoclastic osteolysis. Blood 2004; 104: 2149-2154. 
9. Olson DL, Burkly LC, Leone DR, et al. Anti-alpha4 integrin monoclonal antibody inhibits multiple myeloma growth in a murine model. Mol Cancer Ther 2005; 4: 91-99.

10. Damiano JS, Cress AE, Hazlehurst LA, et al. Cell adhesion mediated drug resistance (CAM-DR): role of integrins and resistance to apoptosis in human myeloma cell lines. Blood 1999; 93: 1658-1667.

11. Noborio-Hatano K, Kikuchi J, Takatoku M, et al. Bortezomib overcomes celladhesion-mediated drug resistance through downregulation of VLA-4 expression in multiple myeloma. Oncogene 2009; 28: 231-242.

12. Cyster JG. Chemokines, sphingosine-1-phosphate, and cell migration in secondary lymphoid organs. Annu Rev Immunol 2005; 23: 127-159.

13. Rivera J, Proia RL, Olivera A. The alliance of sphingosine-1-phosphate and its receptors in immunity. Nat Rev Immunol 2008; 8: 753-763.

14. Spiegel S, Milstien S. The outs and the ins of sphingosine-1-phosphate in immunity. Nat Rev Immunol 2011; 11: 403-415.

15. Schwab SR, Pereira JP, Matloubian M, et al. Lymphocyte sequestration through S1P lyase inhibition and disruption of S1P gradients. Science 2005; 309: 17351739.

16. Pappu R, Schwab SR, Cornelissen I, et al. Promotion of lymphocyte egress into blood and lymph by distinct sources of sphingosine-1-phosphate. Science 2007; 316: $295-298$.

17. Pham TH, Baluk $\mathrm{P}, \mathrm{Xu} \mathrm{Y}$, et al. Lymphatic endothelial cell sphingosine kinase activity is required for lymphocyte egress and lymphatic patterning. $J$ Exp Med 2010; 207: 17-27. 
18. Lee MJ, Van Brocklyn JR, Thangada S, et al. Sphingosine-1-phosphate as a ligand for the G protein-coupled receptor EDG-1. Science 1998; 279: 15521555.

19. Mandala S, Hajdu R, Bergstrom J, et al. Alteration of lymphocyte trafficking by sphingosine-1-phosphate receptor agonists. Science 2002; 296: 346-349.

20. Matloubian M, Lo CG, Cinamon G, et al. Lymphocyte egress from thymus and peripheral lymphoid organs is dependent on S1P receptor 1. Nature 2004; 427: $355-360$.

21. Yagi H, Kamba R, Chiba K, et al. Immunosuppressant FTY720 inhibits thymocyte emigration. Eur J Immunol 2000; 30: 1435-1444.

22. Massberg S, Schaerli P, Knezevic-Maramica I, et al. Immunosurveillance by hematopoietic progenitor cells trafficking through blood, lymph, and peripheral tissues. Cell 2007; 131: 994-1008.

23. Halin C, Scimone ML, Bonasio R, et al. The S1P-analog FTY720 differentially modulates T-cell homing via HEV: T-cell-expressed S1P1 amplifies integrin activation in peripheral lymph nodes but not in Peyer patches. Blood 2005; 106: 1314-1322.

24. Sinha RK, Park C, Hwang IY, et al. B lymphocytes exit lymph nodes through cortical lymphatic sinusoids by a mechanism independent of sphingosine-1phosphate-mediated chemotaxis. Immunity 2009; 30: 434-446.

25. Kabashima K, Haynes NM, Xu Y, et al. Plasma cell S1P1 expression determines secondary lymphoid organ retention versus bone marrow tropism. $J$ Exp Med 2006; 203: 2683-2690. 
26. Brinkmann V, Davis MD, Heise CE, et al. The immune modulator FTY720 targets sphingosine 1-phosphate receptors. J Biol Chem 2002; 277: 2145321457.

27. Pereira JP, Xu Y, Cyster JG. A role for S1P and S1P1 in immature-B cell egress from mouse bone marrow. PLoS One 2010; 5: e9277.

28. Allende ML, Tuymetova G, Lee BG, et al. S1P1 receptor directs the release of immature B cells from bone marrow into blood. J Exp Med 2010; 207: 11131124.

29. Ratajczak MZ, Lee H, Wysoczynski M, et al. Novel insight into stem cell mobilization-plasma sphingosine-1-phosphate is a major chemoattractant that directs the egress of hematopoietic stem progenitor cells from the bone marrow and its level in peripheral blood increases during mobilization due to activation of complement cascade/membrane attack complex. Leukemia 2010; 24: 976985.

30. Pabst O, Herbrand H, Willenzon S, et al. Enhanced FTY720-mediated lymphocyte homing requires $\mathrm{G}$ alpha i signaling and depends on beta 2 and beta 7 integrin. J Immunol 2006; 176: 1474-1480.

31. Kimura T, Boehmler AM, Seitz G, et al. The sphingosine 1-phosphate receptor agonist FTY720 supports CXCR4-dependent migration and bone marrow homing of human CD34+ progenitor cells. Blood 2004; 103: 4478-4486.

32. Kim $\mathrm{CH}, \mathrm{Wu} \mathrm{W}$, Wysoczynski $\mathrm{M}$, et al. Conditioning for hematopoietic transplantation activates the complement cascade and induces a proteolytic environment in bone marrow: a novel role for bioactive lipids and soluble C5bC9 as homing factors. Leukemia 2011. 
33. Pyne NJ, Pyne S. Sphingosine 1-phosphate and cancer. Nat Rev Cancer 2010; 10: $489-503$.

34. Ogretmen B, Hannun YA. Biologically active sphingolipids in cancer pathogenesis and treatment. Nat Rev Cancer 2004; 4: 604-616.

35. Bayerl MG, Bruggeman RD, Conroy EJ, et al. Sphingosine kinase 1 protein and mRNA are overexpressed in non-Hodgkin lymphomas and are attractive targets for novel pharmacological interventions. Leuk Lymphoma 2008; 49: 948-954.

36. Shah MV, Zhang R, Irby R, et al. Molecular profiling of LGL leukemia reveals role of sphingolipid signaling in survival of cytotoxic lymphocytes. Blood 2008; 112: $770-781$.

37. Feng H, Stachura DL, White RM, et al. T-lymphoblastic lymphoma cells express high levels of BCL2, S1P1, and ICAM1, leading to a blockade of tumor cell intravasation. Cancer Cell 2010; 18: 353-366.

38. Garayoa M, Garcia JL, Santamaria C, et al. Mesenchymal stem cells from multiple myeloma patients display distinct genomic profile as compared with those from normal donors. Leukemia 2009; 23: 1515-1527.

39. Garcia-Bernal D, Wright N, Sotillo-Mallo E, et al. Vav1 and Rac Control Chemokine-promoted $\mathrm{T}$ Lymphocyte Adhesion Mediated by the Integrin \{alpha\}4\{beta\}1. Mol Biol Cell 2005; 16: 3223-3235.

40. Sanchez-Aparicio P, Dominguez-Jimenez C, Garcia-Pardo A. Activation of the alpha 4 beta 1 integrin through the beta 1 subunit induces recognition of the RGDS sequence in fibronectin. J Cell Biol 1994; 126: 271-279.

41. Garcia-Bernal D, Sotillo-Mallo E, Nombela-Arrieta C, et al. DOCK2 is required for chemokine-promoted human $\mathrm{T}$ lymphocyte adhesion under shear stress mediated by the integrin alpha4beta1. J Immunol 2006; 177: 5215-5225. 
42. Parmo-Cabanas $\mathrm{M}$, Bartolome RA, Wright $\mathrm{N}$, et al. Integrin alpha4beta1 involvement in stromal cell-derived factor-1alpha-promoted myeloma cell transendothelial migration and adhesion: role of cAMP and the actin cytoskeleton in adhesion. Exp Cell Res 2004; 294: 571-580.

43. Garcia-Bernal D, Dios-Esponera A, Sotillo-Mallo E, et al. RGS10 restricts upregulation by chemokines of $\mathrm{T}$ cell adhesion mediated by alpha4betal and alphaLbeta2 integrins. J Immunol 2011; 187: 1264-1272.

44. Hidalgo A, Weiss LA, Frenette PS. Functional selectin ligands mediating human CD34(+) cell interactions with bone marrow endothelium are enhanced postnatally. J Clin Invest 2002; 110: 559-569.

45. Mazo IB, Gutierrez-Ramos JC, Frenette PS, et al. Hematopoietic progenitor cell rolling in bone marrow microvessels: parallel contributions by endothelial selectins and vascular cell adhesion molecule 1. J Exp Med 1998; 188: 465-474.

46. Yednock TA, Cannon C, Vandevert C, et al. Alpha 4 beta 1 integrin-dependent cell adhesion is regulated by a low affinity receptor pool that is conformationally responsive to ligand. J Biol Chem 1995; 270: 28740-28750.

47. Tadokoro S, Shattil SJ, Eto K, et al. Talin binding to integrin beta tails: a final common step in integrin activation. Science 2003; 302: 103-106.

48. Azab AK, Azab F, Blotta S, et al. RhoA and Rac1 GTPases play major and differential roles in stromal cell-derived factor-1-induced cell adhesion and chemotaxis in multiple myeloma. Blood 2009; 114: 619-629.

49. Fukui Y, Hashimoto O, Sanui T, et al. Haematopoietic cell-specific CDM family protein DOCK2 is essential for lymphocyte migration. Nature 2001; 412: 826831. 
50. Shimonaka M, Katagiri K, Nakayama T, et al. Rap1 translates chemokine signals to integrin activation, cell polarization, and motility across vascular endothelium under flow. J Cell Biol 2003; 161: 417-427.

51. Li QF, Wu CT, Guo Q, et al. Sphingosine 1-phosphate induces Mcl-1 upregulation and protects multiple myeloma cells against apoptosis. Biochem Biophys Res Commun 2008; 371: 159-162.

52. Ledgerwood LG, Lal G, Zhang N, et al. The sphingosine 1-phosphate receptor 1 causes tissue retention by inhibiting the entry of peripheral tissue $\mathrm{T}$ lymphocytes into afferent lymphatics. Nat Immunol 2008; 9: 42-53.

53. Lee MJ, Thangada S, Claffey KP, et al. Vascular endothelial cell adherens junction assembly and morphogenesis induced by sphingosine-1-phosphate. Cell 1999; 99: 301-312.

54. Nombela-Arrieta C, Lacalle RA, Montoya MC, et al. Differential requirements for DOCK2 and phosphoinositide-3-kinase gamma during $\mathrm{T}$ and B lymphocyte homing. Immunity 2004; $21: 429-441$.

55. Nombela-Arrieta C, Mempel TR, Soriano SF, et al. A central role for DOCK2 during interstitial lymphocyte motility and sphingosine-1-phosphate-mediated egress. J Exp Med 2007; 204: 497-510.

56. Ghandour H, Cullere X, Alvarez A, et al. Essential role for Rap1 GTPase and its guanine exchange factor CalDAG-GEFI in LFA-1 but not VLA-4 integrin mediated human T-cell adhesion. Blood 2007; 110: 3682-3690.

57. Durand CA, Westendorf J, Tse KW, et al. The Rap GTPases mediate CXCL13and sphingosine1-phosphate-induced chemotaxis, adhesion, and Pyk2 tyrosine phosphorylation in B lymphocytes. Eur J Immunol 2006; 36: 2235-2249. 
58. Berlin C, Bargatze RF, Campbell JJ, et al. alpha 4 integrins mediate lymphocyte attachment and rolling under physiologic flow. Cell 1995; 80: 413-422.

59. Katayama Y, Hidalgo A, Peired A, et al. Integrin alpha4beta7 and its counterreceptor MAdCAM-1 contribute to hematopoietic progenitor recruitment into bone marrow following transplantation. Blood 2004; 104: 2020-2026.

60. Yasui H, Hideshima T, Raje N, et al. FTY720 induces apoptosis in multiple myeloma cells and overcomes drug resistance. Cancer Res 2005; 65: 7478-7484. 
TABLES

Table 1. Hemodynamic parameters of BM microvessels used for in vivo intravital microscopy analyses. The velocity of the fastest free-flowing cells ( $V \max )$ was determined in each microvessel. Vessel diameters (Dv) were measured using a digital caliper, and mean and critical velocities (Vmean and Vcrit) and wall shear rates (WSRs) were calculated as described in Methods. Data are mean $\pm \mathrm{SEM}$. 


\section{FIGURE LEGENDS}

Figure 1. Expression of S1P receptors on myeloma cells. (A, B, left) The myeloma cell lines NCI-H929, MM1.S, U266, RPMI-8226 and OPM-2, the T cell line Molt-4, and $\mathrm{CD} 138^{+}$myeloma cells purified from 6 different bone marrow aspirates (MM-BM) were tested by RT-PCR for S1P1 or S1P4 expression. (B, right) MM-BM CD138 ${ }^{+}$cells were analyzed by flow cytometry for S1P1 and CXCR4 expression. Vertical line denotes the mean fluorescence intensity of the control antibody. Shown is a representative result out of five different samples. (C, left) K562-S1P1-HA transfectants were either left unstimulated (Control), incubated for $16 \mathrm{~h}$ with S1P (100 nM) or with supernatants from $\mathrm{CD} 138^{+} \mathrm{MM}$ cells, with whole MM-BM samples or with MM-BM plasma. Subsequently, cells were subjected to flow cytometry for detection of S1P1 expression, as specified in Methods. Results from 4 different MM-BM samples are shown. (Right) Same transfectants were either left unstimulated, incubated with S1P or with supernatants from NCI-H929 or MM-BM stroma cultures, or with supernatants from co-cultures of NCI-H929 and MM-BM stroma. S1P1 expression was assessed as in (C). Results from 3 different MM-BM stroma samples are shown.

Figure 2. S1P upregulates CXCL12-stimulated myeloma cell migration. (A) Myeloma cells were subjected for $30 \mathrm{~min}$ (NCI-H929 and MM1.S) or $1 \mathrm{~h}\left(\mathrm{CD} 138^{+}\right.$ MM-BM cells) to chemotaxis assays in response to the indicated stimuli. (B) NCI-H929 cells were transfected with control, CXCR4 or S1P1 siRNA, and transfectants subjected to flow cytometry to analyze CXCR4 and S1P1 expression. Dashed lines show mean fluorescence intensity values obtained with control antibodies. (C, D) NCI-H929 siRNA transfectants were tested in chemotaxis assays to the indicated stimuli (C), or analyzed in chemotaxis assays to supernatants of two different MM-BM stroma samples (D). Data from $(\mathrm{A})$ and $(\mathrm{C})$ represent mean values $+/-\mathrm{SD}(\mathrm{n}=3)$. Data shown on $(\mathrm{D})$ represent 
mean values +/-SD from duplicate measurements of one representative experiment out of three performed. ${ }^{* * *}$ Migration was significantly stimulated compared to control cells (Medium), $\mathrm{p}<0.001$, or ${ }^{* *} \mathrm{p}<0.01 .{ }^{\Delta \Delta \Delta}$ Migration was significantly stimulated compared to samples exposed to CXCL12 alone, $\mathrm{p}<0.001,{ }^{\Delta \Delta} \mathrm{p}<0.01$ or ${ }^{\Delta} \mathrm{p}<0.05$. "** Migration was significantly inhibited, $\mathrm{p}<0.001$, or ${ }^{\star} \mathrm{p}<0.05$.

Figure 3. S1P upregulates CXCL12-stimulated myeloma cell adhesion to $\alpha 4 \beta 1$ and

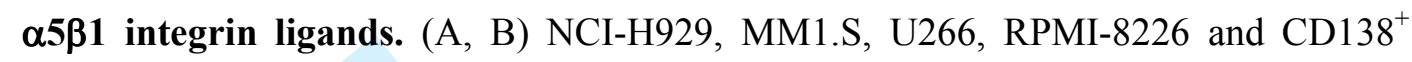
MM-BM cells were subjected to static adhesion assays to the indicated integrin ligands immobilized without (Medium) or with CXCL12, in the absence or presence of soluble S1P (250 nM). (C) NCI-H929 cells were transfected with control, CXCR4 or S1P1 siRNA and tested in adhesion assays to FN-H89. Adhesion data represent mean values +/-SD from at least three experiments done with triplicate samples. ${ }^{* *}$ Adhesion was significantly upregulated compared to unstimulated cells (Medium), $\mathrm{p}<0.01$, or ${ }^{*} \mathrm{p}<0.05$. ${ }^{\Delta \Delta \Delta}$ Adhesion was significantly increased compared to samples exposed to CXCL12 alone, $\mathrm{p}<0.001,{ }^{\Delta \Delta} \mathrm{p}<0.01$ or ${ }^{\Delta} \mathrm{p}<0.05$. " Adhesion was significantly inhibited, $\mathrm{p}<0.01$, or ${ }^{\star} \mathrm{p}<0.05$.

\section{Figure 4. S1P and CXCL12 promote generation of high-affinity $\alpha 4 \beta 1$} conformations. (A) NCI-H929 cells were treated with or without S1P, CXCL12 or $\mathrm{Mn}^{2+}$, followed by incubation with $15 / 7 \mathrm{mAb}$ or with VCAM-1-Fc, and analysis of cell binding by flow cytometry. Insert numbers represent mean fluorescence intensity values. A representative result out of three independent experiments is shown. (B) Nontransfected NCI-H929 cells (left), or cells transfected with the indicated siRNA (right) were incubated for $1 \mathrm{~min}$ at $37^{\circ} \mathrm{C}$ with medium or with the indicated stimuli, and subjected to immunoprecipitation with control (Ctr) or TS2/16 anti- $\beta 1 \mathrm{mAbs}$, followed by immunoblotting with antibodies to polyclonal anti- $\beta 1$ or monoclonal talin antibodies. 
Numbers below gels indicate fold induction in arbitrary units. Representative results out of three experiments are displayed. (C) NCI-H929 cells were exposed to the indicated stimuli and analyzed by immunoprecipitation with control or anti-CXCR4 antibodies, followed by western blotting with antibodies to $\mathrm{G} \alpha_{\mathrm{i}}$ or CXCR4. A representative experiment out of two performed is shown.

\section{Figure 5. Stimulation of $\alpha 4 \beta 1$-dependent myeloma cell adhesion strengthening} and spreading by combined CXCL12 and S1P activities. (A) NCI-H929 and MM1.S cells incubated in the absence or presence of S1P were perfused in flow chambers coated with VCAM-1 immobilized without (Medium) or with CXCL12. Cells were then analyzed for rolling and stable cell arrest (A), or for cell detachment after increasing shear rates $(\mathrm{B})(\mathrm{n}=3)$. Data is presented as indicated in Methods. ${ }^{* * *}$ Adhesion was significantly stimulated compared to cells exposed to medium alone, $p<0.001$ (A). ${ }^{* *}$ Shear resistance data (B) show a representative result out of three independent experiments. (C) NCI-H929 myeloma cells were exposed to the indicated stimuli and subjected to adhesion to FN-H89. Attached cells were fixed and images captured with an inverted microscope. Shown are images from two representative fields per condition (left). (Right) ${ }^{* * *}$ Spreading was significantly increased with respect to control cells (Medium), $\mathrm{p}<0.001$, or to cells exposed to CXCL12 alone, ${ }^{\Delta \Delta} \mathrm{p}<0.01$. (D) NCI-H929 cells incubated with the indicated stimuli were subjected to flow cytometry to determine F-actin content, as stated in Methods.

Figure 6. The DOCK2-Rac1 signalling pathway, but not Rap1, is required for stimulation by CXCL12 or CXCL12/S1P of $\alpha 4 \beta 1$-mediated myeloma cell adhesion. (A) NCI-H929 myeloma cells were transfected with control or DOCK2 siRNA, and subjected to RT-PCR (top), or to Rac1 GTPase assays in response to the indicated stimuli (bottom). (B) Control or DOCK2 siRNA transfectants were tested in VCAM-1 
adhesion assays in the presence of the shown stimuli. (C) Cells were transfected with control or with the indicated Rac1 siRNA, and subjected to RT-PCR (top) or to VCAM1 adhesion assays (bottom). (D) NCI-H929 cells were incubated for 1 min at $37^{\circ} \mathrm{C}$ with the shown stimuli, and subjected to Rap1 GTPase assays. (E) Cells were transfected with Rap1 or control siRNA and transfectants subjected to immunoblotting (top), or tested in adhesion assays to VCAM-1 in the presence of the indicated stimuli. Adhesion data represent mean values +/-SD from three (B and C) or four (E) experiments with triplicate samples. ${ }^{* * *}$ Adhesion was significantly upregulated compared to unstimulated cells (Medium), $\mathrm{p}<0.001,{ }^{* *} \mathrm{p}<0.01$ or ${ }^{*} \mathrm{p}<0.05 .{ }^{\Delta \Delta \Delta}$ Adhesion was significantly increased $\mathrm{p}<0.001$, or ${ }^{\Delta} \mathrm{p}<0.05$, compared to cells incubated with CXCL12 alone. ${ }^{* \star *}$ Adhesion was significantly inhibited compared to that achieved by control siRNA transfectants, $\mathrm{p}<0.001$.

Figure 7. S1P upregulates CXCL12-promoted myeloma cell adhesion to MM-BM stroma and transendothelial migration involving integrins $\alpha 4 \beta 1$ and $\alpha 5 \beta 1$. S1P role in in vivo myeloma cell BM lodging. (A) Myeloma cells were exposed to the indicated stimuli (CXCL12, 150-200 ng/ml; S1P, $250 \mathrm{nM}$ ), and subjected to adhesion to MM-BM stroma, in the absence or presence of function-blocking antibodies to $\alpha 4, \alpha 5$ or $\beta 1$ integrins, or control (Ctr) antibodies. (B) NCI-H929 cells were transfected with control, CXCR4 or S1P1 siRNA, exposed to the indicated stimuli and tested in adhesion to MM-BM stroma. (C) Cells were subjected to transendothelial migration assays in response to the stated stimuli, in the absence or presence of the indicated antibodies. Adhesion and migration data represent mean values +/-SD from experiments with triplicate samples $(\mathrm{A}, \mathrm{C}, \mathrm{n}=3 ; \mathrm{B}, \mathrm{n}=2) .{ }^{* * *}$ Adhesion or migration was significantly upregulated compared to cells exposed to medium, $\mathrm{p}<0.001,{ }^{* *} \mathrm{p}<0.01$, or ${ }^{*} \mathrm{p}<0.05$. ${ }^{\Delta \Delta}$ Adhesion or migration was significantly higher than samples exposed to CXCL12 
alone, $\mathrm{p}<0.01$, or ${ }^{\Delta} \mathrm{p}<0.05$. ${ }^{*}$ Adhesion was significantly inhibited, $\mathrm{p}<0.001$, or ${ }^{\star} \mathrm{p}<0.01$. (D, top) MM1.S cells were incubated with medium (Control) or with S1P and analyzed by flow cytometry for the expression of S1P1, CXCR4 or $\beta 1$ integrin. (Bottom) Same cells were then labelled with DiD and injected into NOD/SCID mice. The number of myeloma cells that lodged in the BM was determined by flow cytometry. (Left) Representative dot-plots. (Right) Relative number of cells lodged in the bone marrow. Mean $\pm \mathrm{SEM} ; \mathrm{n}=4$ mice; $* \mathrm{p}<0.05$. (E) In vivo rolling and arrest of MM cells on the BM microvasculature. NCI-H929 cells transfected with siControl or siS1P1 were fluorescently labeled and injected into NOD/SCID mice prepared for intravital imaging of the calvarial bone marrow. Micrographs are representative images of the collecting venules $(\mathrm{Cv})$ and sinusoids $(\mathrm{S})$ that irrigate the $\mathrm{BM}$ from each experimental group. Free flowing (arrowhead) and arrested cells $(*)$ can be visualized against the autofluorescent bone and dark vessels. Bar graphs show the percentage of passing cells that rolled (defined as those moving below the Vcrit, as described in the Methods section) or arrested for $3 \mathrm{sec}$ or longer. Bars represent Mean $\pm \mathrm{SEM}$ values obtained from the analysis of 21-22 venules from 3-4 mice. *, $\mathrm{p}<0.05$, One-tailed $\mathrm{t}$ test. Scale bar $=100 \mu \mathrm{m}$. 

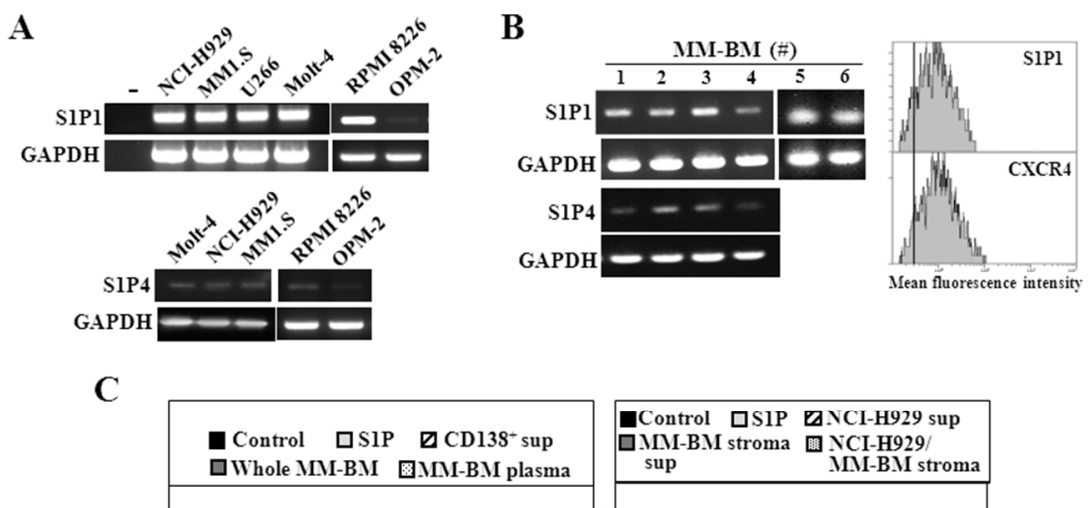

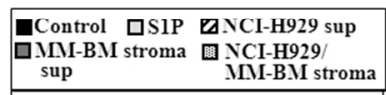
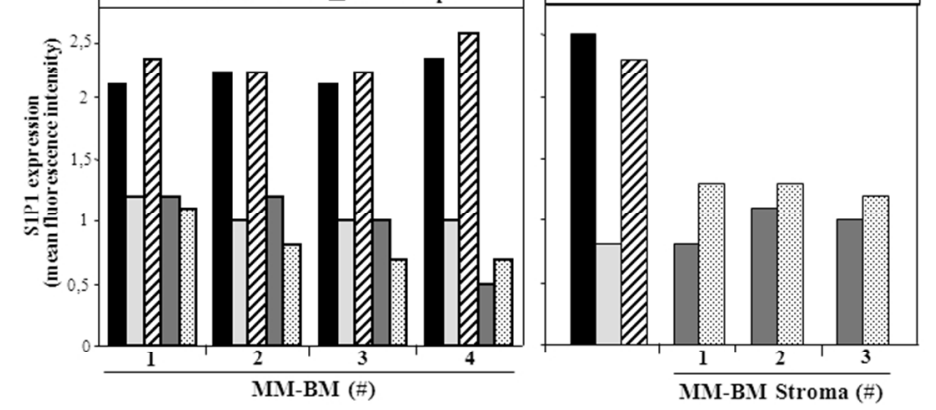

Fig. 1

Figure 1

$254 \times 190 \mathrm{~mm}(96 \times 96$ DPI) 


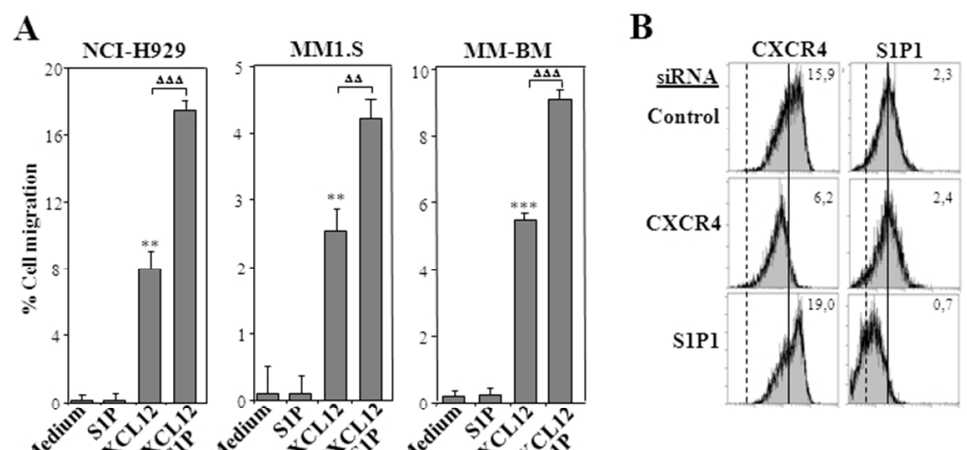

C

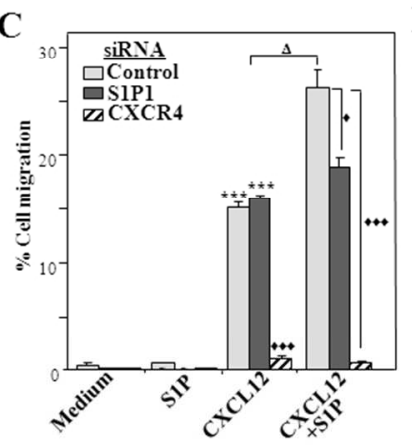

D

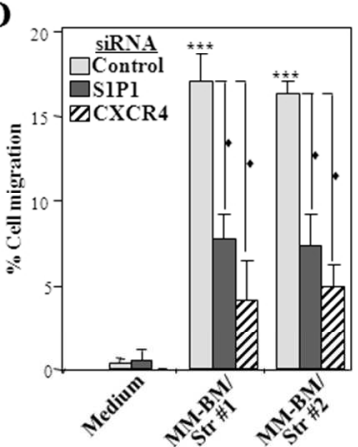

Figure 2

$254 \times 190 \mathrm{~mm}(96 \times 96 \mathrm{DPI})$ 
A

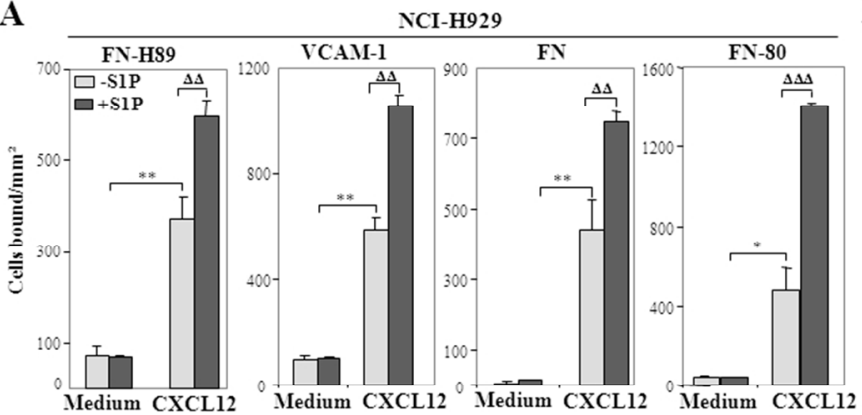

B
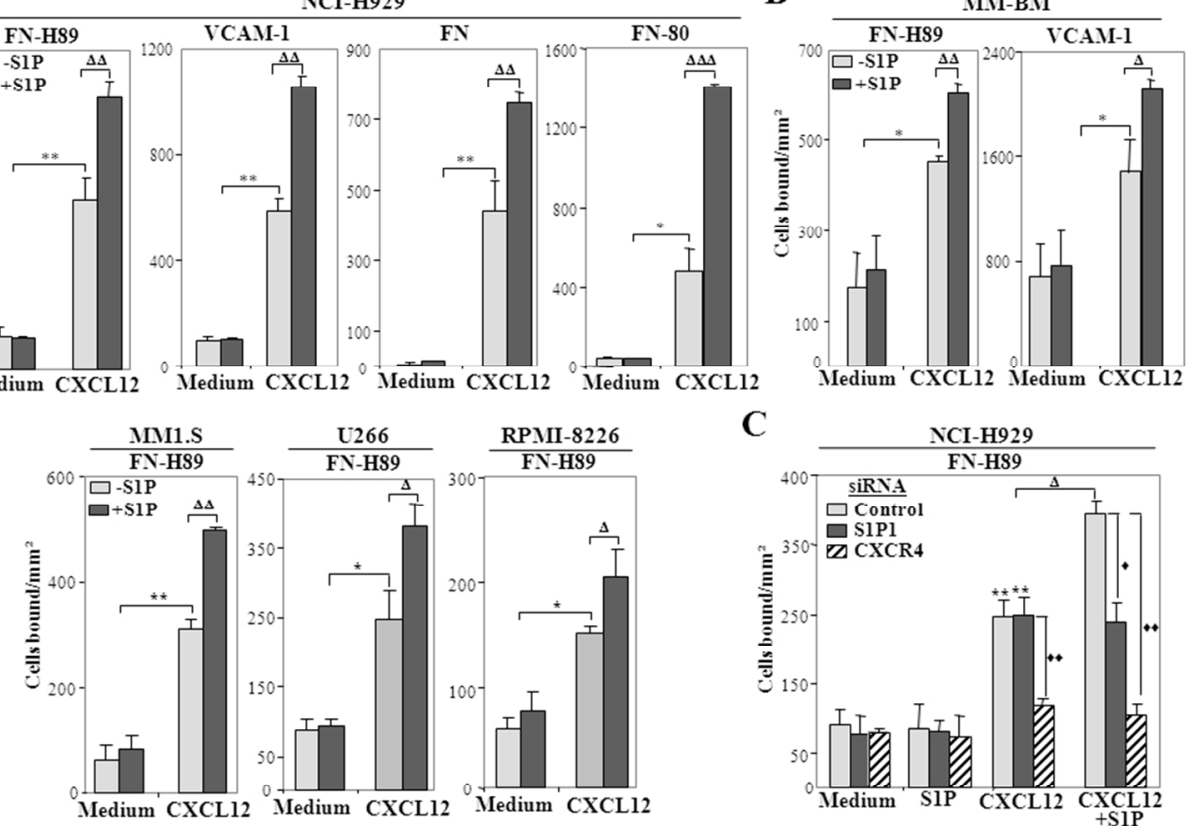

C

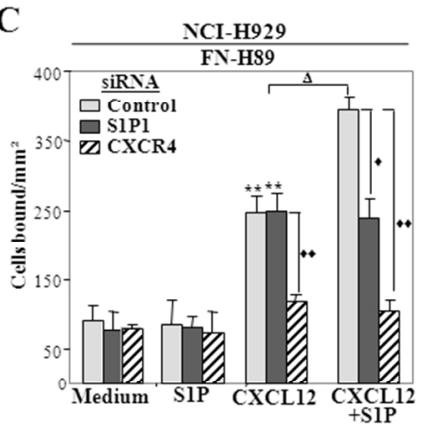

Fig. 3

Figure 3

$254 \times 190 \mathrm{~mm}(96 \times 96$ DPI) 

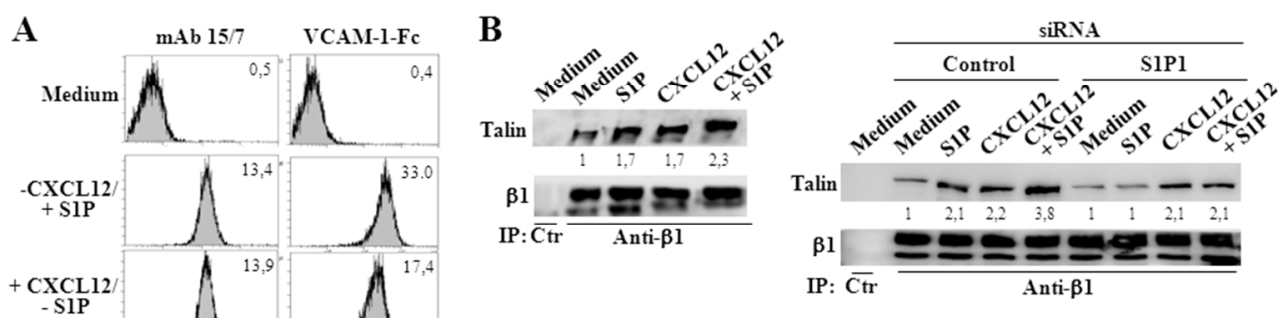

Figure 4 $254 \times 190 \mathrm{~mm}(96 \times 96 \mathrm{DPI})$

C

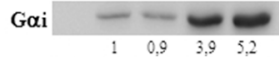

$\mathrm{CXCR} 4$

IP: $\overline{\mathrm{Ctr}}$ Anti-CXCR4 
A

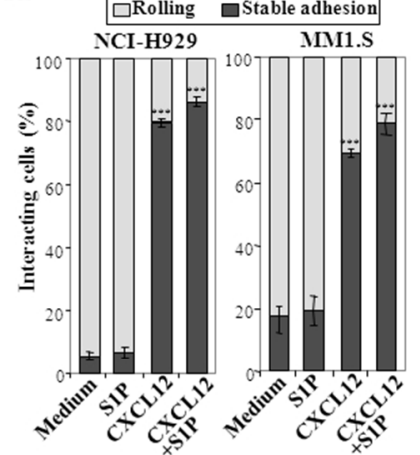

B

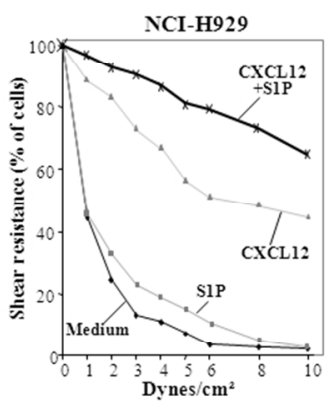

C
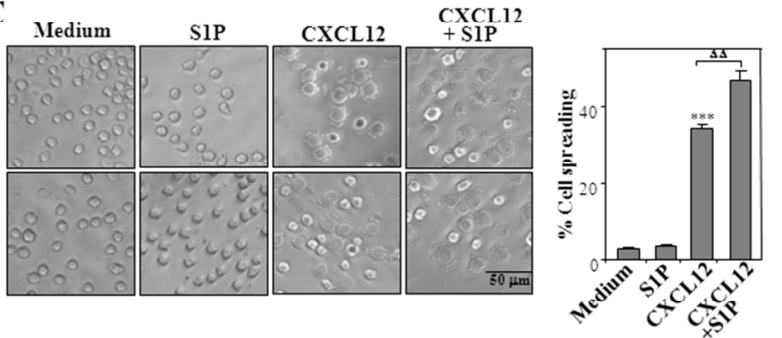

D
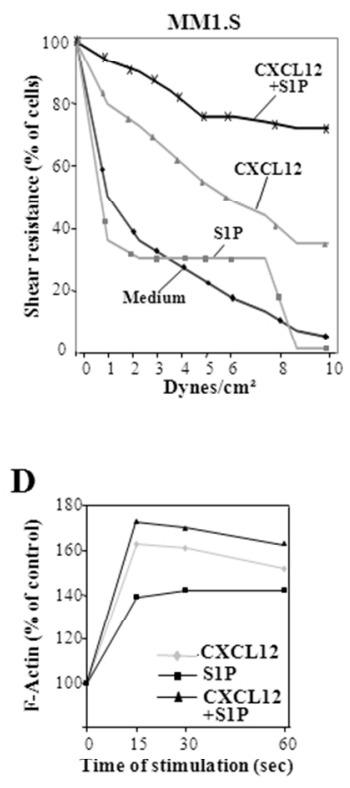

Figure 5

254x190mm (96 x 96 DPI)

H. 
A
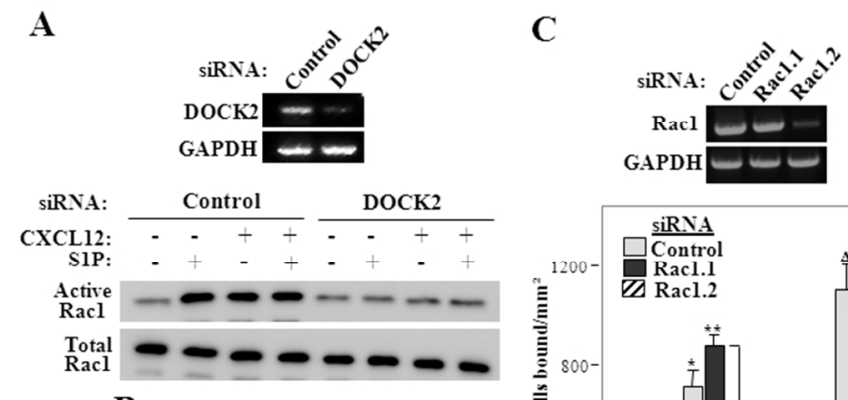

B

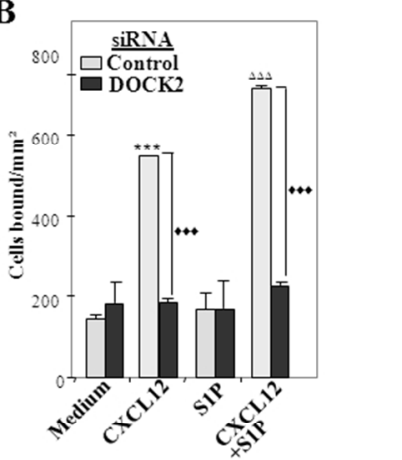

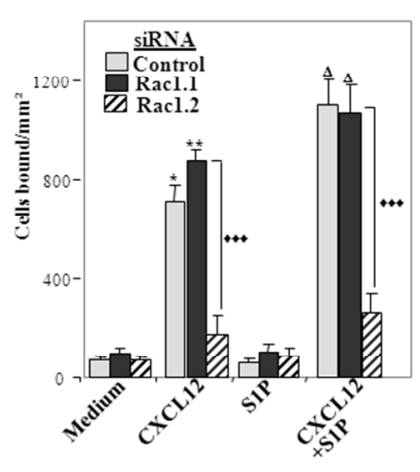

D

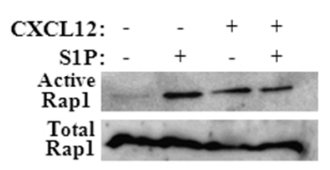

E
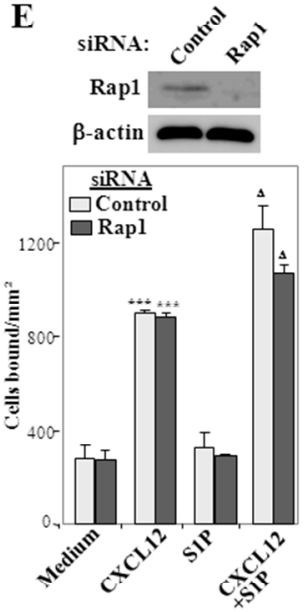

Fig. 6

Figure 6

$254 \times 190 \mathrm{~mm}(96 \times 96 \mathrm{DPI})$

34

35

36

37

38

39

40

41

42

43

44

45

46

47

48

49

50

51

52

53

54

55

56

57

58

59

60

http://mc.manuscriptcentral.com/jpath 
A

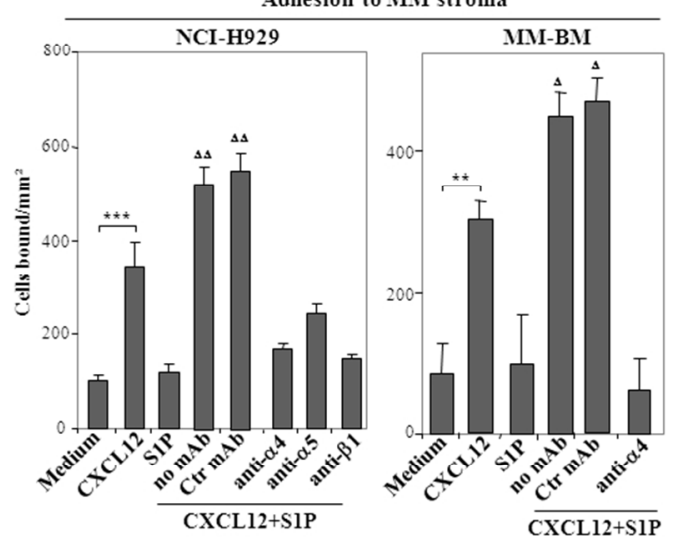

B

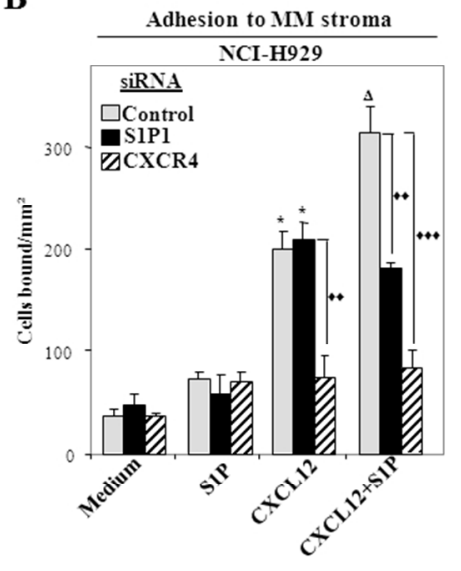

Figure 7

$254 \times 190 \mathrm{~mm}(96 \times 96 \mathrm{DPI})$

34

35

36

37

38

39

40

41

42

43

44

45

46

47

48

49

50

51

52

53

54

55

56

57

58

59

60

http://mc.manuscriptcentral.com/jpath 


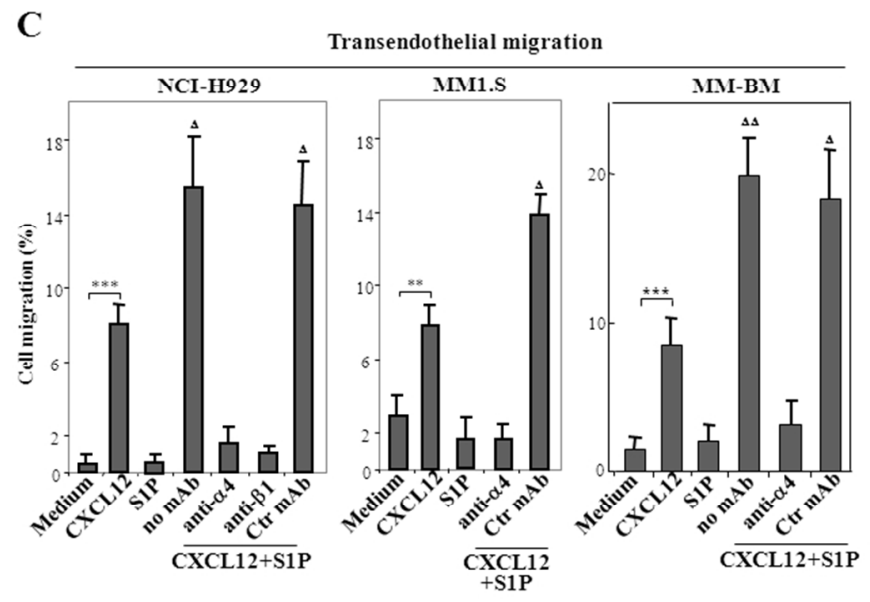

Fig. 7

Figure 7

$254 \times 190 \mathrm{~mm}(96 \times 96$ DPI)

34

35

36

37

38

39

40

41

42

43

44

45

46

47

48

49

50

51

52

53

54

55

56

57

58

59

60

http://mc.manuscriptcentral.com/jpath 
D
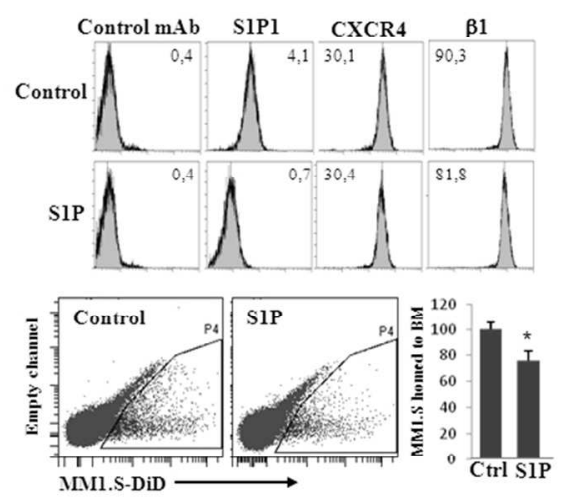

E
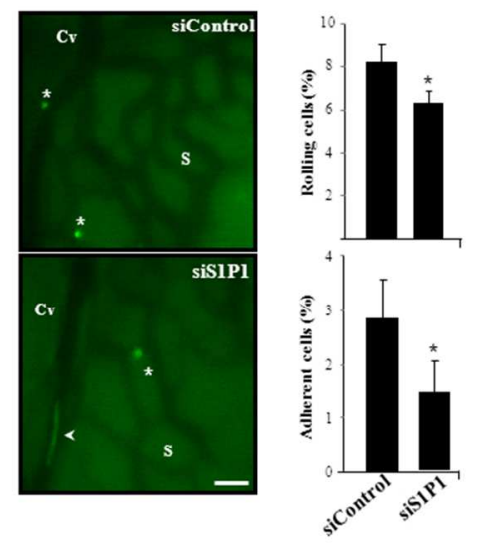

Figure 7

$254 \times 190 \mathrm{~mm}(96 \times 96$ DPI $)$

http://mc.manuscriptcentral.com/jpath 


\section{SUPPORTING INFORMATION}

\section{MATERIALS AND METHODS}

Myeloma cell lines, antibodies and reagents. The human myeloma cell lines NCIH929, MM1.S, U266, RPMI 8226 and OPM-2, the T cell line Molt-4, and K562 erythroleukemia cells were cultured in RPMI 1640 medium and $10 \%$ fetal bovine serum (Biowhittaker, Verviers, Belgium). Control P3X63, anti- $\alpha 4$ HP2/1, anti- $\beta 1$ TS2/16 and Lia1/2.1 mAb were gifts from Dr. Francisco Sánchez-Madrid (Hospital de la Princesa, Madrid, Spain). Polyclonal anti- $\beta 1 \mathrm{~A}$ antibodies and the anti- $\beta 1 \mathrm{mAb} 15 / 7$ were gifts from Drs. Guido Tarone and Ronen Alon (Turin University, Italy; and Weizmann Institute of Science, Rehovot, Israel, respectively). Anti-Rac1 and anti- $\alpha 5$ antibodies were from BD Biosciences Pharmingen (San Diego, CA), anti-talin, anti-HA and anti- $\beta$ actin from Sigma-Aldrich (St Louis, MO), and anti-Rap1 and anti-Gai from Santa Cruz Biotechnology (Santa Cruz, CA). Antibodies against S1P1 were purchased from Santa Cruz Biotechnology and R\&D Systems (Minneapolis, MN). Specificity was validated using K562 transfected with the S1P1 cDNA. Anti-CXCR4 antibodies and CXCL12 were obtained from R\&D Systems, S1P from Alexis Biochemicals (Carlsbad, CA), FTY720 phosphate from Cayman Chemical (Ann Arbor, MI) and fatty acid-free BSA from Sigma.

RNA interference, vectors and RT-PCR. siRNA for DOCK2 [38], Rac1.1 and Rac1.2 (targeted to bases 529-550 and 383-404, respectively, on racl gene sequence), S1P1 (targeted to bases 532-553), CXCR4 (targeted to bases 601-622), Rap1 (targeted to bases 103-123 on RaplA gene sequence), or control siRNA [39] were purchased from Ambion (Austin, TX) or from Dharmacon (Lafayette, CO). S1P1-HA or Rap1-HA vectors in pcDNA3.1 were from The Missouri S\&T cDNA Resource Center (Rolla, MO). Amplification of DOCK2 was performed as described \{Garcia-Bernal, 2006 
\#664\}, whereas S1P1 and S1P4 amplifications were performed using the following primers: S1P1 forward, 5'-GGCTGGAACTGCATCAGTGCG-3', reverse, 5'GAGCAGCGCCAGCGACTTCTCAGAGC-3'; S1P4 forward, 5'CCTTCAGCCTGCTCTTCACT-3', reverse, 5'-AAGAGGATGTAGCGCTTGGA-3'. Immunoprecipitation and immunoblotting. Cells were lysed (Triethanolamine pH 8.0 $20 \mathrm{mM}, \mathrm{NaCl} 150 \mathrm{mM}$, EDTA $1 \mathrm{mM}$, digitonin 1\%, in the presence of protease and phosphatase inhibitors), and supernatants incubated with antibodies followed by coupling to protein G-Sepharose (Sigma). Proteins were resolved by SDS-PAGE, transferred to membranes and incubated with primary antibodies and horseradish peroxidaseconjugated secondary antibodies. Proteins were visualized using SuperSignal chemiluminiscent substrate (Pierce, Rockford, IL).

Flow cytometry. Cells $\left(2-3 \times 10^{5}\right)$ were incubated for 30 min with primary antibodies, and upon the washing steps, Alexa 488-conjugated anti-mouse secondary antibodies (Molecular Probes) were added and samples incubated for additional $30 \mathrm{~min}$. Cells were subsequently analyzed in a Coulter Epics XL cytofluorometer.

http://mc.manuscríptcentral.com/jpath 


\section{FIGURE LEGENDS}

Figure S1. S1P1 internalization in $\mathrm{K562}$ cells expressing transfected S1P1, and S1P role in myeloma cell migration. (A) K562 cells were left untransfected, or transfected with S1P1-HA or Rap1-HA vectors (The Missouri S\&T cDNA Resource Center, Rolla, MO), followed by immunoblotting with anti-HA antibodies. (B) K562 cells expressing S1P1-HA were incubated for $16 \mathrm{~h}$ with the indicated concentrations of S1P and subsequently subjected to flow cytometry with anti-S1P1 antibodies. (C) NCI-H929 myeloma cells were subjected for the indicated times to chemotaxis assays in response to the shown stimuli. A representative result out of four independent experiments is shown. (D) NCI-H929 cells were incubated with S1P for the indicated times and subsequently analyzed by flow cytometry using antibodies to CXCR4 or $\beta 1$ integrin.

Figure S2. Upregulation by S1P and FTY720 of CXCL12-promoted myeloma cell adhesion mediated by the integrin $\boldsymbol{\alpha} \mathbf{4} \boldsymbol{\beta}$. (A) NCI-H929 myeloma cells were subjected to adhesion to FN-H89 immobilized without (Medium) or with CXCL12, in the absence or presence of soluble S1P (left), or to chemotaxis assays (right), using fatty acid-free BSA in the adhesion/migration medium. (B) NCI-H929 myeloma cells were subjected to adhesion assays to VCAM-1 immobilized without (Medium) or with CXCL12, in the absence or presence of the indicated concentrations of soluble S1P. (C) NCI-H929 cells were subjected to adhesion assays to FN-H89 immobilized without (Medium) or with CXCL12, in the absence or presence of the indicated concentrations of soluble FTY720 or S1P. ${ }^{* * *}$ Adhesion was significantly upregulated compared to unstimulated cells (Medium), $\mathrm{p}<0.001 .{ }^{\Delta \Delta}$ Adhesion was significantly increased compared to samples exposed to CXCL12 alone, $\mathrm{p}<0.01$, or ${ }^{\Delta} \mathrm{p}<0.05$. 
Table 1. Hemodynamic parameters of BM microvessels used for in vivo intravital microscopy analyses.

\begin{tabular}{|c|c|c|c|c|c|c|}
\hline & $V \max$ & $\mathrm{Dr}$ & Vmean & WSR $\left(s^{-1}\right)$ & Verit & $\begin{array}{l}\text { No. of } \\
\text { ressels }\end{array}$ \\
\hline siControl & $1403 \pm 127$ & $54,8 \pm 2$ & $710 \pm 64$ & $104 \pm 9$ & $193 \pm 17$ & 21 \\
\hline siS1P1 & $1737 \pm 125$ & $64,8 \pm 2$ & $876 \pm 63$ & $109 \pm 8$ & $204 \pm 15$ & 22 \\
\hline
\end{tabular}

Table 1

Table 1

254×190mm (96 x 96 DPI) 
A

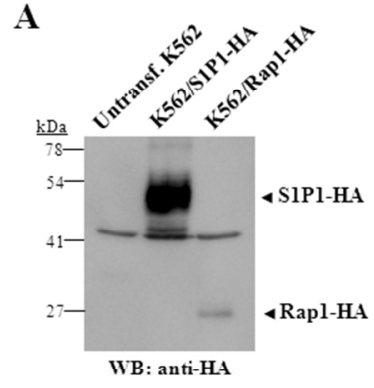

C

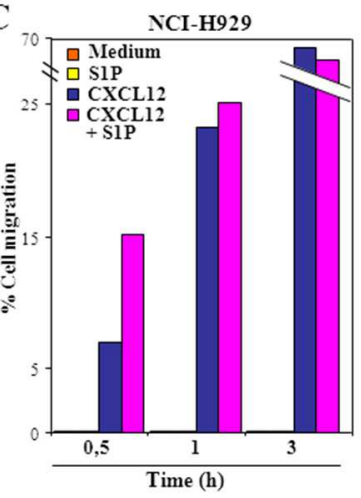

B

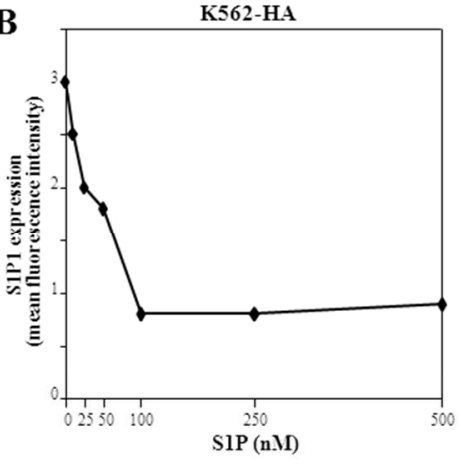

D

\begin{tabular}{cccrr} 
& \multicolumn{4}{c}{ Hours with S1P $(250 \mathrm{nM})$} \\
\cline { 2 - 5 } & 0 & 6 & 24 & 48 \\
\hline CXCR4 & 54 & 51 & 52 & 54 \\
$\beta 1$ & 158 & 161 & 162 & 169 \\
\hline
\end{tabular}

Supplementary Figure 1

Supplementary figure 1 $254 \times 190 \mathrm{~mm}$ (96 x 96 DPI) 

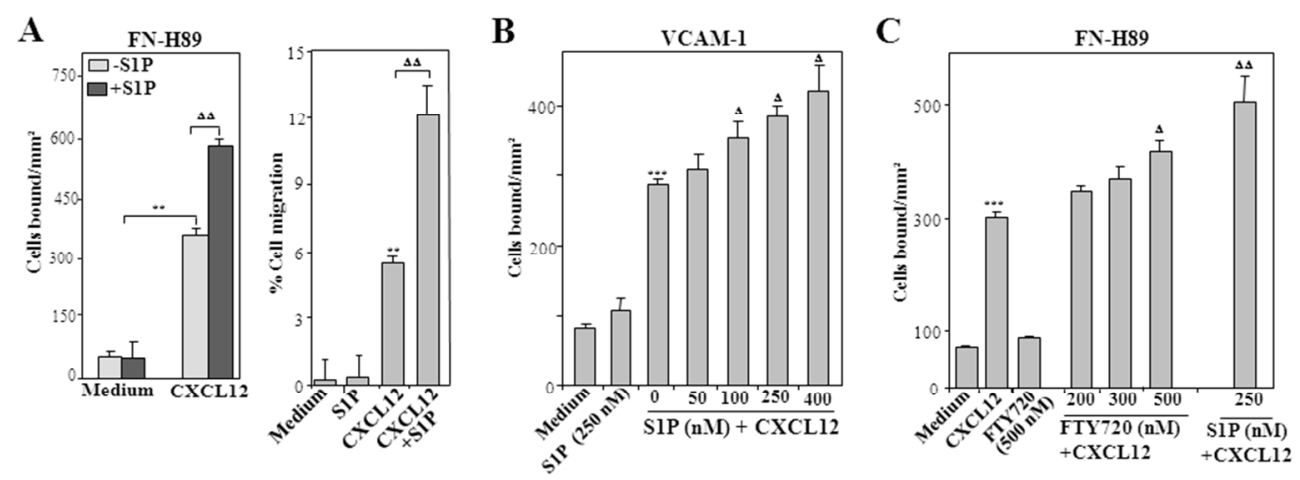

Supplementary Figure 2

Supplementary figure 2 $254 \times 190 \mathrm{~mm}$ (96 x 96 DPI) 


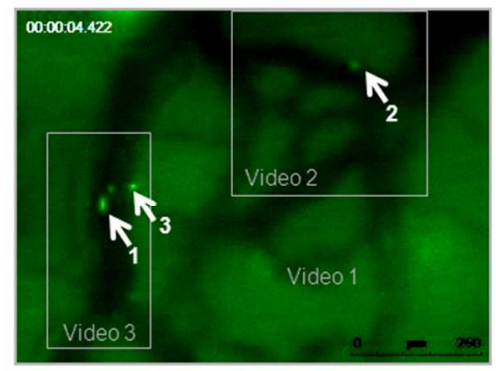

Supplementary videos:

Supplementary video 1 shows a representative field with free-flowing (arrow 1), rolling (arrow 2) and arrested (arrow 3) cells. Supplementary videos 2 and 3 are enlarged views from supplementary video 1 , showing cells that display rolling or arrest, respectively

\section{Supplementary video} 254x190mm (96 x 96 DPI) 